\title{
Molecular Classification of Iraqi Breast Cancer Patients and Its Correlation with Patients' Profile
}

\author{
Khudair J. Al-Rawaq* \\ Manwar A. Al-Naqqash* \\ Mustafa K. Jassim**
}

\author{
MBChB, DMRT \\ MBChB, DMRT, MSc Pathology \\ $\mathrm{MBChB}$
}

Abstract:

Background: Breast cancer is a complex, multifaceted disease encompassing a great variety of entities that show considerable variation in clinical, morphological and molecular attributes.

Objective: The aim of this study to evaluate patients' molecular profile (Estrogen receptor, Progesterone receptor, HER2/neu and Ki-67).

Fac Med Baghdad

2016; Vol.58, No.3

Received: May,2016

Accepted: July.2016
Patients \& Methods: This is a cross-sectional descriptive study was done in Baghdad oncology teaching hospital from December 2015 to April 2016, carried on 100 breast cancer female patients with their age range from 27 to 73 years old and with their histopathology reports and (IHC) results.

Results: The highest incidence of breast cancer among patients in 5th (40-49 years) and 6th (50-59 years) decades of life both groups are (32\%), estrogen and progesterone values were observed (74\% and $75 \%$ respectively) and 69 patients (69\%) with Ki-67 $\geq 14$.

Conclusions: Most of the breast cancer patients in the current study were estrogen and progesterone (Hormonal) positive, and Luminal B-like was the most common molecular subtype (53\%) due to high Ki67 index. There was a strong correlation between estrogen and progesterone in the studied patients with highly significant $\mathrm{P}$ value $<0.0001$.

Keywords: Breast cancer, Luminal B like, estrogen, progesterone.

\section{Introduction:}

Breast cancer is a major public health problem for women throughout the world. In the United States, breast cancer remains the most frequent cancer in women and the second most frequent cause of cancer death. In 2012, it was estimated there were 226,870 new cases of breast cancer, with 39,510 deaths (1). In Europe, breast cancer was also the most common form of cancer seen in 2006, with 429,900 new cases representing $13.5 \%$ of all new cancers (2). While in Iraq and according to Ministry of Health/Iraqi cancer registry: 2011, breast cancer ranks the first with percentage of $34.44 \%$ (3). Breast cancer is a heterogeneous disease witch results from a series of genetic and epigenetic events that lead to dysregulation of cell growth, circumvention of apoptosis, and development of the ability to invade the underlining tissue through the basement membrane. The causes of these events remain largely unknown, although epidemiologic studies have implicated lifestyle, environmental, and germ-line genetic factors in predisposition to this disease. Familial forms comprise approximately $20 \%$ of all breast cancers and appear to have a distinctive pathogenesis dependent on the particular susceptibility gene involved (4) (5). Increasing our understanding of molecular biology and gene expression signatures of breast cancer continues to improve prevention, detection, and treatment strategies for

*Dept. of Surgery, College of Medicine, University of Baghdad.

** Baghdad teaching Hospital, Dept. of oncology .

mustafa.Rawaq@gmial.com breast cancer patients. Estrogen and progesterone receptor expression are the most important and useful predictive factors currently available. Current assays for ER and PgR are performed using IHC techniques, which have the advantages of not being confounded by endogenous estrogens, can be correlated with histologic finding to eliminate the possibility that the assessment was done on noncancerous tissue, can be performed on paraffin embedded tissues, and do not have tumor size as a limiting factor. The HER2/neu protooncogene (also called c-erbB-2) located on chromosome 17 codes for a transmembrane glycoprotein, which has tyrosine kinase activity and is homologous to the EGFR (6) and it is amplified or overexpressed in up to $20 \%$ of human breast carcinomas. Overexpression of the protein is associated with tumor aggressiveness and decreased disease-free survival in node-positive patients, with variable prognostic significance among node-negative patients. Staining for overexpression of HER2/neu is interpreted on a 0 to $3+$ scale. The available data suggest that the majority of 0 to 1 staining is clearly negative and $3+$ is clearly positive, while the classification of those patients with $2+$ staining remains uncertain. Microarraybased gene expression of breast cancer has demonstrated that there are multiple molecular subtypes of breast cancer (luminal A like, luminal B like, Her2 positive and basal-like) and these subtypes correlate with prognosis (7)(8). The use of proliferation marker Ki-67 together with ER, PgR and Her2 
status may be used as surrogates to define the intrinsic subtype of breast cancer (9). Table (1) defines the agreed surrogate definitions of the intrinsic subtypes of breast cancer using the St. Gallen criteria.

Table (1): Surrogate definitions of intrinsic subtypes of breast cancer.

\begin{tabular}{cc}
\hline Intrinsic subtype & Clinic-pathological definition \\
\hline Luminal A & All of: \\
& ER and PgR Positive, HER2 negative, \\
Ki-67 low(<14) \\
Recurrence risk is low based on multi- \\
gene expression assay
\end{tabular}

\section{Patients and Methods:}

This is a cross-sectional descriptive study was conducted in Baghdad oncology teaching hospital from December 2015 to April 2016, carried on 100 breast cancer female patients at different age groups with their histopathology reports and immunohistochemichal (IHC) results including ER, PgR, HER2/neu and Ki-67. The patients enrolled in this study were already diagnosed with breast cancer either on adjuvant chemotherapy, hormonal therapy or on regular follow up, all of them were females their ages ranged from 27 to 73 years old with a mean age of 50.96 years and median of 51 years. The data of all the patients were obtained from the laboratory of the Baghdad Oncology Teaching Hospital and form cancer research department of the hospital which included the histopathological reports that confirm their diagnosis regarding breast subtypes, grading and staging. Also, immunohistochemical (IHC) reports that confirm their hormonal status (ER, PgR HER2) and the proliferation index (KI-67). The patients in this study underwent surgical intervention either by biopsy or mastectomy with axillary clearance, and then the formalinfixed paraffin-embedded tissue blocks were sent to the hospital laboratory for H\&E and IHC.All the data analyzed through statistical package for social sciences (SPSS) version 16, and all the quantitative variables were presented as mean and standard deviation, while qualitative variables were presented as frequency and percentages. Spearman's rho or Pearson test was used to evaluate the statistical difference. A P-value $<0.05$ was considered significant.

\section{Results:}

The total number of the patients in this study was 100 breast cancer female patients with their ages ranged from 27 to 73 years with a mean age \pm SD $(51 \pm 10)$ years, and the results showed the highest incidence of breast cancer among patients in 5th (40-49 years) and 6th (50-59 years) decades of life both are (32\%), while the lowest incidence of breast cancer among patients in 3rd decade of life $(2 \%)$ as seen in figure (1). In regards to the tumor size our results revealed that T1 was $(28 \%)$, T2 was $(56 \%)$, T3 was $(15 \%)$ and T4 was $(1 \%)$. Also our results found that $\mathrm{Nx}$ was $(33 \%)$, N0 was (16\%), N1 was $(25 \%)$, N2 was (17\%) and N3 was $(9 \%)$. Breast cancer tissues expressing positive immunohistochemical ER and PgR values were observed in $74 \%$ and $75 \%$ respectively as seen in table (2). In regards of the immunohistochemicetry of Her2/ neu our results showed that 26 patients $(26 \%), 28$ patients (28\%), 30 patients $(30 \%)$ and 16 patients $(16 \%)$ for score 0 , $+1,+2,+3$ respectively. Score +3 considered positive, score 0 , +1 considered negative, while +2 equivocal and it need FISH test to confirm its positive result. Also our results revealed that 31 patients $(31 \%)$ with Ki-67<14, while 69 patients $(69 \%)$ with $\mathrm{Ki}-67 \geq 14$.

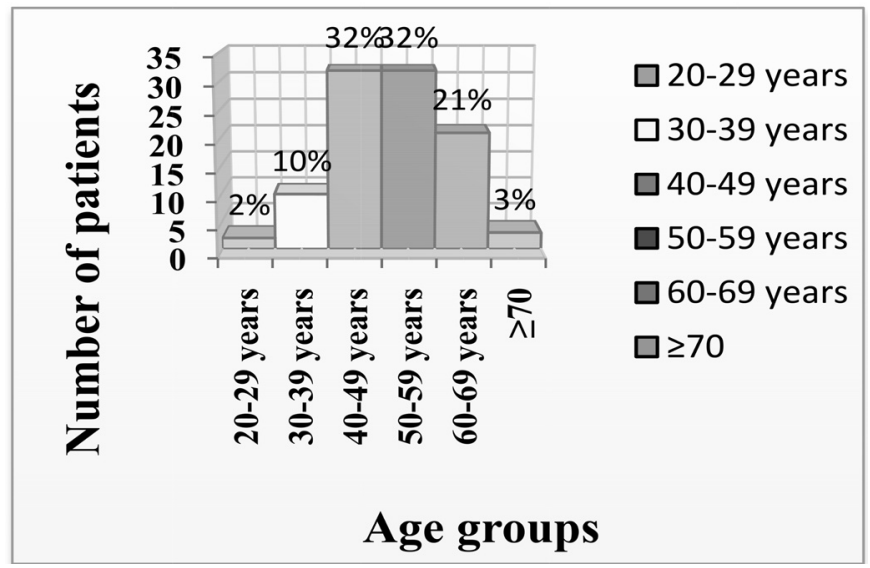

Figure (1): Age distribution in the studied breast cancer patients.

Table (2): Hormonal receptors (ER and PgR) status in the studied breast cancer patients

\begin{tabular}{|c|c|c|c|c|c|}
\hline \multirow{2}{*}{$\begin{array}{l}\text { Hormonal } \\
\text { Status }\end{array}$} & \multicolumn{4}{|c|}{ Score } & \multirow{2}{*}{ Total (\%) } \\
\hline & 0 & +1 & +2 & +3 & \\
\hline ER & $26(26 \%)$ & $14(14 \%)$ & $17(17 \%)$ & $43(43 \%)$ & $100(100 \%)$ \\
\hline PgR & $25(25 \%)$ & $11(11 \%)$ & $20(20 \%)$ & $44(44 \%)$ & $100(100 \%)$ \\
\hline
\end{tabular}


The current study illustrated a statistically significant correlation between the tumor size and Her2/neu with $\mathrm{P}$ value $=0.013$, and a weak correlation between the lymph nodes and the tumor size with insignificant $\mathrm{P}$ value $=0.181$. There was a strong correlation between ER and PgR with highly significant $\mathrm{P}$ value $<0.0001$, and a strong correlation between ER and Her2 with significant $\mathrm{P}$ value $=0.009$. On the other hand, our results reported a weak correlation between PgR and Her2 with insignificant $P$ value $=0.165$ as seen in table (3).

Table (3): Correlation among (ER, PgR and Her2/neu) in the studied breast cancer patient.

\begin{tabular}{|c|c|c|c|c|}
\hline \multirow{4}{*}{$\begin{array}{c}\text { Spearman's rho } \\
\text { Correlation } \\
\text { Coefficient } \\
\text { Sig. (2-tailed) } \\
\text { N }\end{array}$} & & $\begin{array}{c}\text { ER } \\
\text { Expression }\end{array}$ & $\begin{array}{c}\text { PR } \\
\text { Expression }\end{array}$ & $\begin{array}{l}\text { HER2 NEU } \\
\text { Expression }\end{array}$ \\
\hline & $\begin{array}{c}\text { ER } \\
\text { Expression }\end{array}$ & $\begin{array}{c}1.000 \\
100\end{array}$ & $\begin{array}{l}.670 \\
.000 \\
100\end{array}$ & $\begin{array}{l}.259 \\
.009 \\
100\end{array}$ \\
\hline & $\begin{array}{c}\text { PR } \\
\text { Expression }\end{array}$ & $\begin{array}{l}.670 \\
.000 \\
100\end{array}$ & $\begin{array}{c}1.000 \\
100\end{array}$ & $\begin{array}{l}.140 \\
.165 \\
100\end{array}$ \\
\hline & $\begin{array}{l}\text { HER2 NEU } \\
\text { Expression }\end{array}$ & $\begin{array}{l}.259 \\
.009 \\
100\end{array}$ & $\begin{array}{l}.140 \\
.165 \\
100\end{array}$ & $\begin{array}{c}1.000 \\
100\end{array}$ \\
\hline \multicolumn{5}{|c|}{$\begin{array}{l}P \text { value of } E R \text { and } P g R \text { correlation }<0.0001 \\
P \text { value of } E R \text { and Her } 2 \text { correlation }=0.009 \\
P \text { value of } P g R \text { and Her } 2 \text { correlation }=0.165\end{array}$} \\
\hline
\end{tabular}

According to the molecular subtypes of breast cancer using the St. Gallen criteria 2013 in regard with the immunohistochimesry (IHC) of the studied patients. The results showed that Luminal B-like were 53 patients (53\%), Luminal A-like were 29 patients (29\%), Triple negative were 15 patients (15\%) and HER2 overexpressed were 3 patients (3\%) as seen in figure (2).

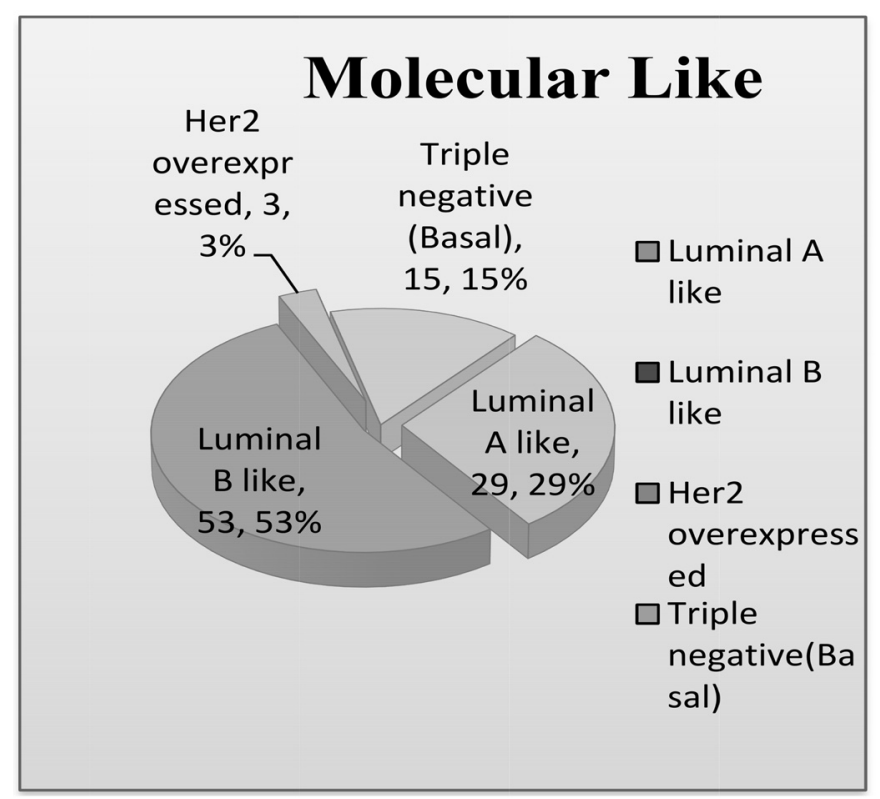

Figure (2): Molecular subtypes distribution in studied breast cancer patients.

\section{Discussion:}

This is a cross sectional descriptive study which deals with the molecular classification of breast cancer of Iraqi breast cancer patients and its correlation with tumor stage and patients profile. Breast cancer incidence generally increases with age. Age of the patient is an important factor both for the occurrence and management of the disease with $95 \%$ of all new breast cancer cases developing in women aged 40 years or older (American cancer society, 2012) (1), which was consistent with our results. Also, our result was consistent with Al-Khafaji AH.2010 (10) which stated that the peak frequency was recorded in age period (40-49 years). Similar age incidences for breast cancer in Iraq were recorded in other reports (11) (12) (13). Tumor size is defined by measuring the tumor in at least two dimensions, with the greatest dimension used for tumor staging. The size of the primary tumor ranks among the strongest predictors of distant metastasis and disease-free and overall survival. Although tumor size correlates strongly with the presence and number of involved axillary lymph nodes, it is clearly an independent prognostic factor. Our results were consistent with Al-Naqqash MA. 2009 (13) a study revealed that T2 was the most common tumor size in Iraqi cancer patients. Also, AlKhafaji AH. 2010 (10) a study that demonstrated tumor sizes in the Iraqi group were $7 \%, 53 \%, 25 \%$ and $15 \%$ for T1, T2, T3 and $\mathrm{T} 4$ respectively, and $\mathrm{T} 2$ the most common recorded tumor size, which was similar to our results. On the other hand, our results greatly differ from what has been reported in the United States for both white and African Americans (14), the median tumor size was $1.6 \mathrm{~cm}$ and $1.9 \mathrm{~cm}$ for white and African Americans respectively. Also, different results were seen with Vassilios et al., 2004 (15) and Russell et al., 2006 (16). Lymph nodes involvement is the most important predictor of disease recurrence (17), and of all prognostic factors, nodal status continues to be the strongest predictor of disease-free and overall survival and is the primary factor that governs breast cancer staging (18). Prognosis worsens as the number of positive nodes increases (19). Our results were consistent with other studies from Iraq (12) (20) (12) (21). Also, Al-Naqqash MA. 2009 (13) reported that N1 (44\%), and it was the highest frequency of lymph nodes involvement which was consistent with our results as N1 was the highest recorded frequency concerning lymph nodes involvement. Estrogens have been hypothesized to play a dual role in breast cancer risk. Directly or indirectly, they may promote risk through stimulating growth of mammary cells and inducing DNA damage. Estrogens have also been proposed to play a role in reducing risk of developing breast cancer through the activation of tumor suppressor genes critical to the maintenance of genomic stability and repair of DNA damage (22). In the current study, breast cancer tissues expressing positive immunohistochemical ER and PgR values were observed in $74 \%$ and $75 \%$ respectively. Our results were compatible with Al-Naqqash MA.2009 (13) which showed that $83 \%$ were ER and PgR positive, and consistent with Elyass 
TY.2012 (20) which reported that $72 \%$ and $68 \%$ for ER and PgR respectively. Furthermore, our results similar to Al-Sarraf FS. 2015 (23) which stated that $75 \%$ and $72.5 \%$ for ER and PgR respectively. Different results were seen by Al-Sanati M. 2009 (24) a study form Kurdistan/Iraq who showed that 58\% were ER and PgR positive, and another study by Al-Khafaji AH.2010 (10) which showed similar results to Al-Sanati with (58\% and $61.5 \%$ for ER and PgR respectively). ER and PgR were criteria for sample collection in the present study. Any case without this test was excluded from the beginning of the study; this is the reason of such difference, Al-Sanati M. 2009 (24) included the procedure of immunohistochemical detection of ER and PgR in her study. According to Her2/neu our results reported that the negative score $(0,+1)$ were the highest score, while score +3 were the lowest and these results agreed with Al-Sarraf FS. 2015 (23) (25) (26).

Regarding the prevalence and percentage of the Luminal A and B subtypes, our results are inconsistent with Cheang et al. 2009 (27) a study appear to distinguish Luminal A-like from Luminal B-like by using the immunohistochimesry of the hormonal status (ER, PgR, Her2/neu) and Ki-67 index cutoff point $14 \%$ which stated that $(28 \%),(19 \%),(17 \%)$ and $(27 \%)$ for Luminal A-like, Luminal B-like, Her2/neu overexpressed and Triple negative(Basal) respectively, while it is consistent with our results regarding Her $2 /$ neu overexpressed which is the lowest recorded frequency. The current study was compatible with Al-Sarraf FS. 2015 (23) which stated that Luminal B-like was the most common molecular subtype. This finding agreed with El- Fatemi H and Chahbouni1 S. 2012 (28) a study from Morocco which recorded a close result (42\%) of breast cancer was Luminal B-like. In regards to the correlation between the tumor size and Her2/neu, our study showed a statistically significant correlation with $\mathrm{P}$ value $=0.013$, which was inconsistent with Al-SarrafFS.2015 (23). Multiple studies have shown a strong correlation between primary tumor size and axillary nodal involvement (29) (30), which are inconsistent with our results, due to a limited number of patients in this study (100 cases) and regardless the hormonal status (ER, PgR and HER2) the cases are not homogenously distributed and that's the reason of such a difference. According to hormonal status our results showed a strong correlation between ER and PgR with highly significant $\mathrm{P}$ value $<0.0001$, which was consistent with (Al-Khafaji AH. 2010; Elyass TY. 2012).

\section{Conclusions:}

Highest incidence of breast cancer in the studied patients was seen $\geq 40$ years $(32 \%)$ in 5 th, 6 th decades of life, and the most common tumor size according to TNM staging system was T2 (56\%), beside the most common assessed axillary lymph nodes was N1 (25\%). Luminal B-like was the most common molecular subtype of the breast cancer patients in the studied group (53\%) mostly due to high Ki-67 index, while Her2 overexpressed was the lowest (3\%). Most of the breast cancer patients in the current study were ER and PgR (Hormonal) positive $74 \%, 75 \%$ respectively, had a negative $(0,+1) \mathrm{Her} 2 /$ neu status (54\%) and Ki-67 $\geq 14$ (69\%). There was a strong correlation between ER and PgR in the studied patients with highly significant $\mathrm{P}$ value $<0.0001$. ). Also a strong correlation between ER and Her2 with significant $\mathrm{P}$ value $=0.009$.

\section{Author Contributions:}

Dr. Khudair J. Al Rawaq: Study conception and critical revision.

Dr. Manwar A. Al Naqqash: Acquisition of data analysis and interpretation of data, and study design.

Dr. Mustafa K. Jassim: Data collection, drafting manuscript.

\section{References:}

1. American Cancer Society. Breast Cancer Facts \& Figures 2009-2010. Atlanta: American Cancer Society; 2012.

2. Ferlay J, Autier P, Boniol M, et al. Estimates of the cancer incidence and mortality in Europe in 2006. Ann Oncol. 2007; 18(3):581.

3. Iraqi Cancer Registry 2011, Ministry Of Health, Iraqi Cancer Board, Baghdad.

4. Antonio AC, Easton DE, Models of genetic susceptibility to breast cancer. Oncogene 2006; 25(43):5898.

5. Wooster R, Weber BL. Breast and onvarian cancer. $N$ Engl $J$ Med 2003; 348(23):2339.

6. Slamon DJ, Clark GM, Wong SG, et al. Human breast cancer: correlation of relapse and survival with amplification of the HER-2/neu oncogene. Science 1987;235(4785):177182.

7. Perou CM, Sorlie T, Eisen MB, et al. Molecular portraits of human breast tumours. Nature 2000;406:747-752.

8. Sorlie, T., Perou, C. M., Tibshirani, R., et al. (2001). Gene expression partners of breast carcinomas distinguish tumor subclasses with clinical implications. Proc. Natl. Acad. Sci. USA, 98, 10869-10874.

9. Goldhirsch A., Winer, E. P., Coates, A. S., et al. (2013b). Personalizing the treatment of women with early breast cancer: highlights of the St Gallen International Expert Consensus of the primary Therapy of Early Breast Cancer 2013. Ann. Oncol., 24, 2206-2223.

10. Al-Khafaji Ali Hussein. Immunohistochemical expression of Estrogen, Progesterone receptors, P53 and Ki67 in Iraqi and Syrian breast cancer patients, A clinicopathological study. Baghdad-Iraq; 2010.

11. Yalda M.I.: PCR Study of BRCA1 BRCA2 in Correlation to Immunohistochemical Expression of P53, Estrogen and Progesterone Receptor in Breast Cancer. A thesis submitted to the College of Medicine and committee of graduated studies of Baghdad University in partial fulfillment for the degree philosophy in pathology 2009. 
12.Al-Anbari S. S: Correlation of the clinicopathological presentations in Iraqi breast cancer patients with the findings of biofield breast cancer diagnostic system (BDS), Her-2 and Ki-67 immunohistochemical expression, a thesis submitted to the college of medicine and the committee of post graduate studies of the University of Baghdad in partial fulfillment of the requirement for the degree of Ph D in Pathology.2009.

13. Al-Naqqash Manawar Abdulelah: the role of c-myc oncogene as a prognostic marker in breast cancer patients evaluated by immunnohistochemistry and in situ hypridization (prospective study). Baghdad-Iraq. University of Baghdad College of medicine; 2009.

14. Haffty BG, Alvarez-Franco $M$, Silber $A$, et al: BCRA1 and BCRA2 mutations in breast cancer patients of African American descent.; Breast Cancer Res Treat. 2000; 64:61.

15. Vassilios J Papantoniou, Michael A Souvatzoglou, Varvara $J$ Valotassio et al. Relationship of cell proliferation (Ki-67) to $99 m T c(V)$ DMSA uptake in breast cancer. Breast Cancer Res, 2004, 6: 56-62.

16. Russell Burcombe, George D Wilson, Mitch Dowsett, et al. Evaluation ofKi-67 Proliferation and apoptotic index before, during and afterneoadjuvant chemotherapy for primary breast cancer. Breast Cancer Research, 2006, 8(3): R31.

17. Kumar V,Cotran RS., Robbins basic pathology seventh edition, 2003;p:711-712.

18. American Joint Committee on Cancer. AJCC cancer staging manual, 7th ed. New York:Springer Science and Business Media LLC, 2010.

19. Rosai and Ackerman's Surgical Pathology; breast (chapter 20); ninth edition; volume II 2004, PP: 1763-1839.

20. Elyass Tamarah Yasseen Mohsin: Molecular Study of Human Mammary Tumor Virus and Immunohistochemistry of Hormonal Receptors in women with Breast Carcinomas. Baghdad-Iraq; 2012.

21. Yussef Faten Talb. Assessment of Her2/neu status in breast cancer using both immunohistochemistry and chromogenic insitu hybridization. A thesis submitted to the college of medicine university of Baghdad in partial fulfillment of the requirements for the degree of Master of Science in pathology. Baghdad-Iraq. 2014.

22. William DF, Kelly M, Ping S, et al: Estrogen Receptor Status in BRCA1- and BRCA2-Related Breast Cancer The Influence of Age, Grade, and Histological Type. Clinical Cancer Research March 2004 10; 2029.

23. Al-Sarraf Fatima Sabeeh. Immunohistochemical Expression of ER, PR, Her2/neu and Ki67 in Breast Carcinoma. Clinicopathological Study. Baghdad-Iraq; 2015.

24. Al-Sanati M. PCR study of BRCA1, BRCA2 in correlation to immunohistochemical expression of P53, estrogen and progesterone receptors in breast cancer. A PhD thesis Baghdad. 2009.
25. AL-Bedairy I., AL.Azzawie H., AL-Kazaz A. et al. Immunohistochemical evaluation of human epidermal growth factor receptor 2 and estrogen and progesterone receptors in Iraqi breast carcinoma women. International Journal of Advanced Research, 2014, Vol. 2, Issue 6, 168-177.

26. Penault-Llorca, F. and Viale, G. Pathological and molecular diagnosis of triple-negative breast cancer: a clinical perspective. Annals of Oncology. 2012, 23: 19-22.

27. Cheang MC, Chia SK, Voduc D et al. Ki67 index, HER2 status, and prognosis of patients with luminal B breast cancer. J Natl Cancer Inst 2009; 101: 736-750.

28. El-Fatemi H., Chahbounil S. Luminal B tumors are the most frequent molecular subtype in breast cancer of North African women: an immunohistochemical profile study from Morocco. Diagnostic pathology. ; 2012, 7:170.

29. Voogd AC, Coebergh JW, Repelaer van Driel OJ, et al. The risk of nodal metastases in breast cancer patients with clinically negative lymph nodes: a population-based analy sis. Breast Cancer Res Treat 2000;62(1):63-69.

30. Greco M, Crippa F, Agresti R, et al. Axillary lymph node staging in breast cancer by 2-fluoro-2-deoxy -D-glucosepositron emission tomography : clinical evaluation and alternative management. J Natl Cancer Inst 2001;93(8):630 635. 